\title{
Integration of a Rapid Prototyping System in a MET Curriculum
}

\author{
Jack Zecher \\ Professor of Mechanical Engineering Technology \\ Indiana University Purdue University Indianapolis (IUPUI)
}

\begin{abstract}
Rapid Prototyping is a process that quickly transforms a CAD model into a physical part. This new technology has made a dramatic impact in industry by helping to speed up the product development cycle. Opportunities also exist for this new technology to have a sizable impact in the educational environment. Unlike the type of impact that this technology has had in industry, the educational benefits of incorporating this technology lie primarily in the student's improved comprehension of three-dimensional CAD models. By allowing students to physically grasp the results of their work, rather than to merely view an image on a CRT, also raises the students' level of interest in their coursework and adds a level of excitement to the learning process.

This paper examines how a Genisys rapid prototyping system, that was partially funded by the National Science Foundation's Division of Undergraduate Education through grant DUE-9650418, was introduced into the MET curriculum at Indiana University Purdue University at Indianapolis. The approach taken was to introduce this technology into several different courses rather than to devote a single class to this technology. By gradually introducing students to this new technology in several different courses, rapid prototyping is used to reinforce other components of the courses. The experiences of introducing this new technology into the curriculum during this first year are discussed, along with other positive impact that the system has made.
\end{abstract}

\section{Introduction}

Users of CAD systems have always desired a means to produce three-dimensional hardcopies of their CAD models. Manufacturers of rapid prototyping equipment have finally provided this capability. There are currently several different processes used in commercially available systems: stereolithography, laminated object manufacturing, selective laser sintering, fused deposition modeling and 3D printing are the most prevalent. Industrial firms have been making use of rapid prototyping for a variety of purposes. Several of these include: production of patterns for use in the casting industry; construction of concept models used in design reviews or to communicate with subcontractors for quotes; and usage of models in client presentations.

Incorporation of a rapid prototyping system in an educational setting provides several opportunities that are similar to industry. Students are able to fairly quickly build mockups of their designs, in order to evaluate their fit, functionality and in some cases use as 
patterns in the school's foundry. The touch and feel of a prototype can provide enormous motivation to students as well as instantly reveal if the CAD model actually defined the part as intended. The rapid prototyping process, therefore, provides a tool which allows students to go directly from "art to part".

\section{System Installation}

In January, 1996 a Stratasys/Genisys fused deposition modeling system was installed in a lab that was being renovated. The focus of the lab is to provide an environment that supports high-end CAD/CAM type work. This involves the use of CAD software such as ProEngineer ${ }^{\circledR}, 3$ Dstudio ${ }^{\circledR}$ and AutoCAD ${ }^{\circledR}$. In addition to the CAD software, several multimedia software packages used in Technical Graphics related classes and projects are also used on the computers in this lab. In order to effectively run this mix of software, Pentium, Pentium Pro and Pentium II machines were installed in this lab.

The majority of the computers in this lab run under Microsoft's NT® operating system. However, in order to accommodate several software packages that do not yet run under NT, two of the machines run under Windows95®. The Genisys software is installed on one of the computers that runs under the NT operating system that is physically adjacent to the rapid prototyping machine. The rapid prototyping machine is connected to this computer through its network card and appears to the computer as if it were a printer on the network.

\section{Basic Steps involved in creating RP models}

Although the type of material used to construct physical prototypes varies with the different processes mentioned above, the initial steps in the process of creating a rapid prototype model are common for all of these processes. The first step, that is common for all types of systems involves defining the part to be built in a CAD environment as a surface or solid model. At IUPUI this is done by constructing the part as a solid model using either AutoCAD ${ }^{\circledR}$ or ProEngineer ${ }^{\circledR}$ software.

After the solid model is completed, the bounding surfaces of the CAD model are then automatically discretized into a collection of triangular facets by the CAD program being used. This faceted information is written to a disk file in a format known as the STL format ${ }^{1}$. Additional support structures must be added (in the form of STL data) to some models if they have overhanging portions which would otherwise become distorted during the build process. This process is done automatically during a later step by the Genisys software. The rapid prototyping system's software reads the STL file and uses it to calculate "slice" data, which are lines of intersection of the STL facets with horizontal planes located at constant heights. The slice information is the path that describes the outline of the part to be built. Depending on the type of process used, a laser or modeling head is driven along this path and in the interior until the model is built up, one layer at a time. 


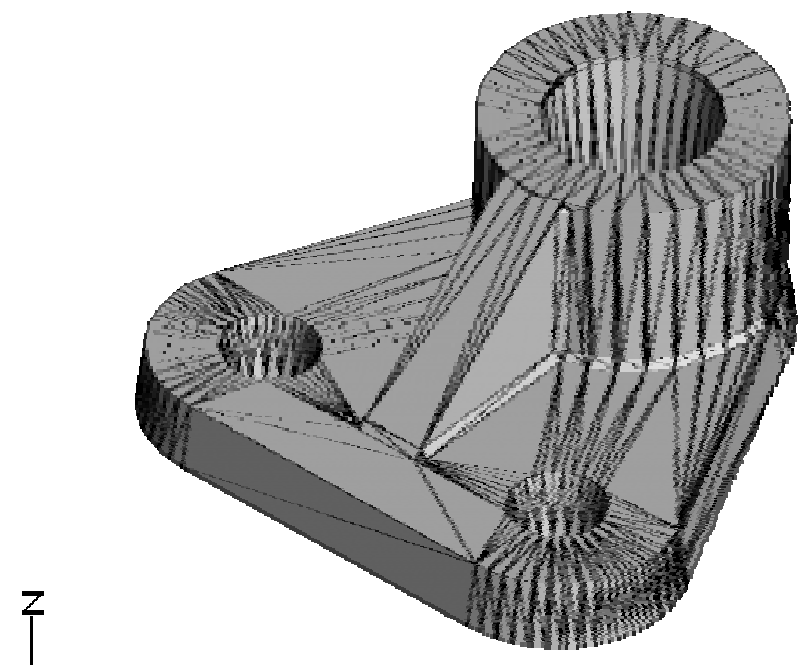

Figure 1 Solid Model discretized into triangular facets (STL data).

After the Genisys rapid prototyping machine has finished building the part, it can immediately be removed from the machine. Any support structures that were added are then broken away, leaving the finished part.

\section{TG 110 - The student's first look at rapid prototyping}

The basics concepts of rapid prototyping are first introduced in the MET curriculum as part of a first semester course - TG 110-Drafting Fundamentals. This is a 3 credit hour course that concentrates on the procedures and practices used in technical graphics, so that design ideas can be adequately communicated and produced. AutoCAD software is used to develop the concepts and skills necessary to work in both 2-D and 3-D environments.

A lecture was added toward the end of this course that gives students a general overview of the different types of technologies employed in rapid prototyping. The advantages of using rapid prototyping techniques to achieve a more rapid product development cycle along with lowering product development costs are discussed. This is followed by a lecture/lab demonstration of the process of converting a 3DCAD data model into an actual physical prototype. By this time in the semester, students are familiar with the process of defining 3D solid models using AutoCAD. The discussion is focused on how the 3D CAD model is converted into a format that the rapid prototyping system can use. This consists of writing out a STL file and then moving this file to the computer that is connected to the rapid prototyping system. The Genisys software, that reads the STL file and actually drives the rapid prototyping machine is then demonstrated. A small model is actually built during the lab portion. However, since the machine takes approximately $1 / 2$ hour to build the part, a completed model, along with its support structures still in tack, is used to show the process of removing the support structures. 


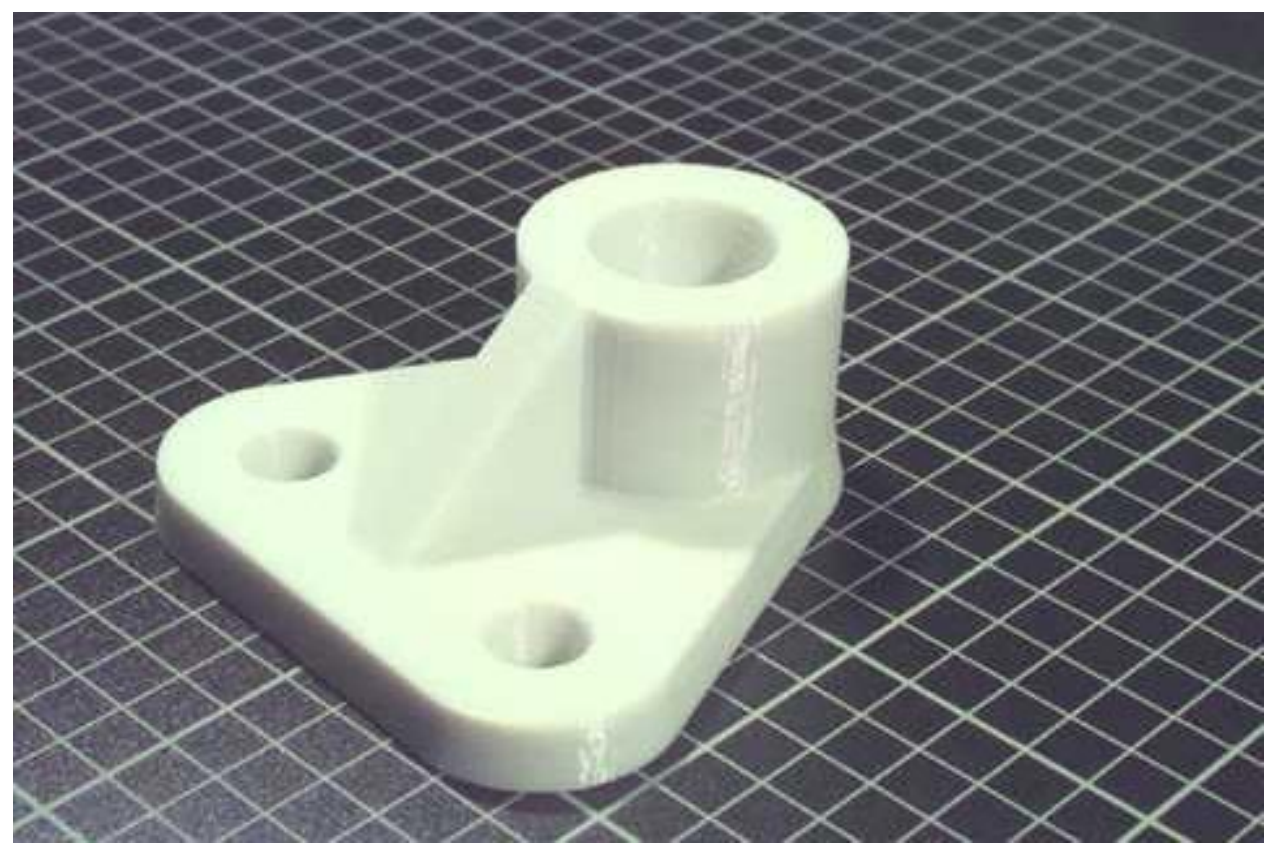

Figure 2 Rapid prototyping part that was modeled using AutoCAD

\section{MET 328 - A more in-depth look at rapid prototyping}

During their junior year, MET students are required to take MET 328-CAD/CAM for Mechanical Design and Drafting. This course uses the ProEngineer ${ }^{\circledR}$ software to introduce students to the concepts of developing parametric based solid models. The inclusion of a discussion on Rapid Prototyping fits in very nicely in this course since a portion of this course includes a discussion of the various formats of data files that are used to transfer geometric data, such as IGES and DXF, between different CAD and CAM programs. Currently there is a partial duplication of the material that is presented in TG110, since the rapid prototyping system was not present when the MET 328 students took TG110. However, additional topics are included in the MET 328 lectures that are not covered in the TG 110 course. These include: control of accuracy in the CAD to STL file translation process ${ }^{2}$, support structure control, reverse engineering, and use of rapid prototype models as patterns for cast metals.

During their final project of the semester, students are given the option to use the rapid prototyping system to build a physical prototype of their CAD model. It is up to the student to select their own final project, therefore, not all of the models produced on the rapid prototyping system are the same. During the first two semester in which the rapid prototyping system has been used, approximately two-thirds of the students have elected to make rapid prototype models of their projects. Figure 3 shows a model of a portion of a crankshaft and its connecting rod and piston that were made on the rapid prototyping system. 


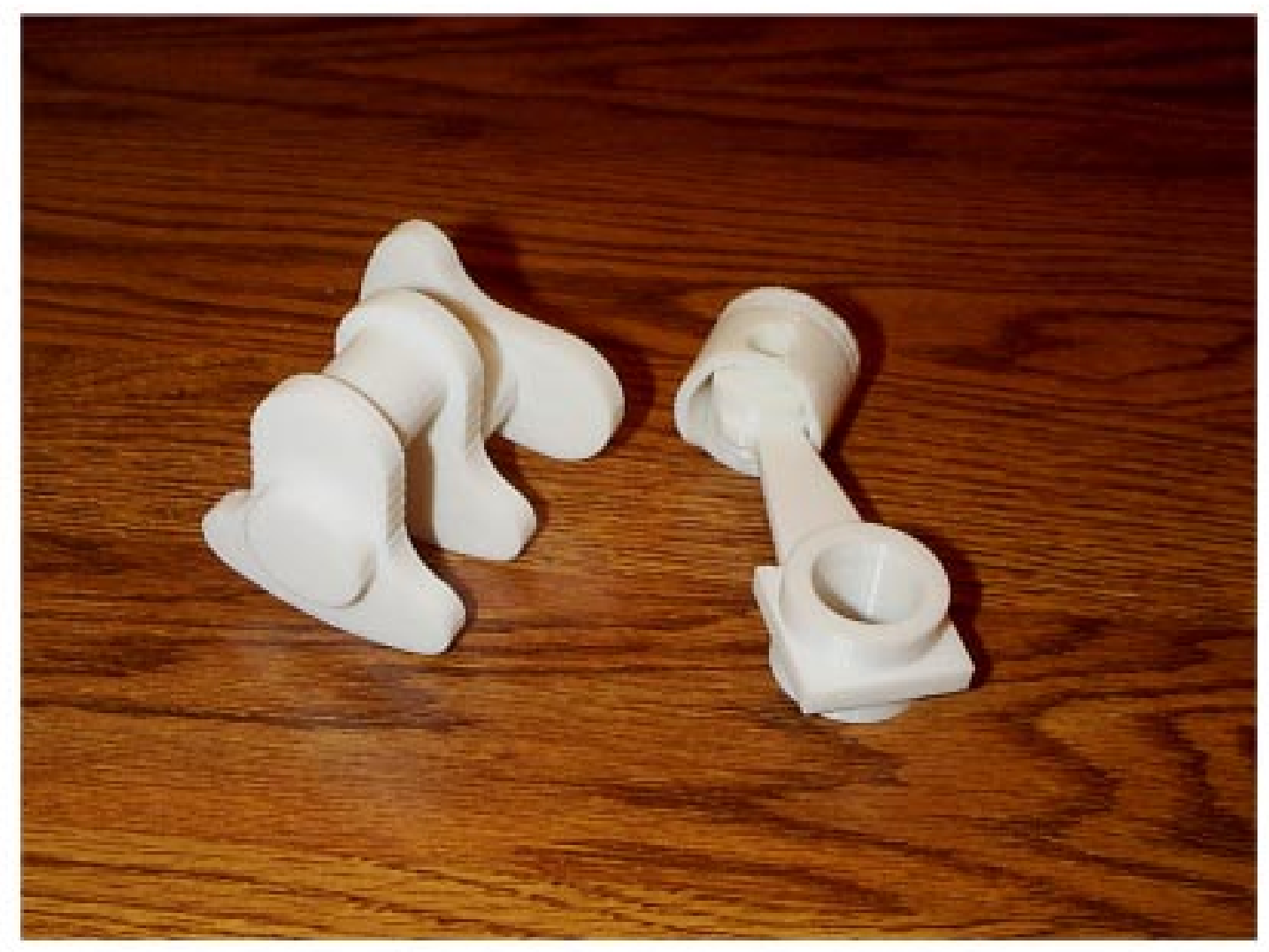

Figure 3 Example of final project in the MET 328 class

\section{Other Educational Uses}

Two other classes have made limited use of the rapid prototyping machine. The MET 240-Basic Foundry class has used a rapid prototype model to illustrate how a sand casting pattern can be made. Although the type of polymer that is used in the Genisys system is not appropriate to be used in investment casting, a portion of one of the lectures on investment casting now includes discussion of how some types of rapid prototyping systems can make investment casting molds. Several students in the MET 414-Design of Mechanical Projects class have made prototypes on the system. It is expected, that as the students who are now learning the capabilities on the system in the TG 110 and MET 328 classes advance on to the MET 414 class that more use of the system will be made. 


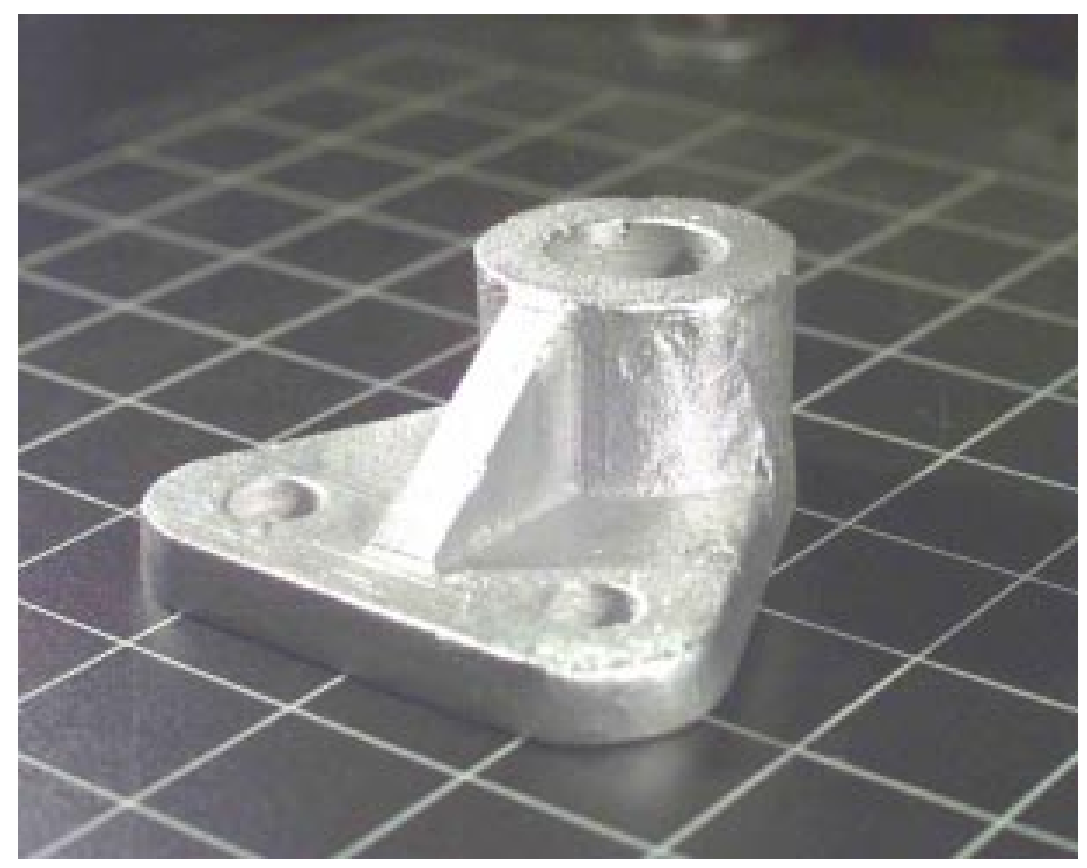

\section{Figure 4 Aluminum casting made in MET 240 from the Rapid Prototype model shown in Figure 2}

\section{Conclusion}

The initial goal of introducing a rapid prototyping system into the curriculum was to enhance several CAD related courses. This goal is presently being accomplished in the TG 110 and MET 328 courses. It is expected that further use of the system will be made in courses like the MET 414 class previously mentioned as well as independent project courses and several other courses outside the MET student's curriculum. In addition, demonstration of the equipment during open house events and the school's summer Minority Engineering Advancement Program have generally met with a high level of excitement. During events like these, it is much easier for the general public to appreciate a CAD model if they can hold a physical prototype as they are observing an image on the CRT.

\section{References:}

1 3D Systems, Inc., StereoLithography Interface Specification, Oct. 1989, 3D Systems publication, Valencia, CA

2 Fadel, G. M. and Kirschman, C., Accuracy Issues in CAD to RP Translations, internet publication: http://www.eng.clemson.edu/dmg/fadel.html

Jack Zecher, P.E., Professor of Mechanical Engineering Technology at Indiana University Purdue University Indianapolis has been with the University since 1983. Professor Zecher teaches courses in the mechanical design field as well as CAD related subjects. He has authored the book Computer Graphics for CAD/CAM Systems, published by Marcel Dekker. 